Atsushi Tanaka (Kwansei Gakuin University)

\title{
Unconventional Monetary Policy in Japan: An Empirical Study on its Effectiveness
}

\section{Introduction}

This paper examines the effectiveness of unconventional monetary policy in Japan. The past literature on this topic is reviewed, and also some empirical findings are presented from the econometric analysis in this paper.

Since the burst of the economic bubble in the early 1990s, Japan has been suffering from the slow, and sometimes negative, growth for two decades. To fight against the economic problem in this so-called "lost two decades" the Bank of Japan, the Japanese central bank, exhausted conventional measures of monetary policy and has often used some unprecedented measures. This is the unconventional monetary policy in Japan and its main measure is called "quantitative easing."

The unique economic situation and the unconventional monetary policy in Japan drew the attention of many economists around the world, as it was a curious economic experiment for them. The policy created great controversy over its effectiveness and possible side effects.

In the early 2000s, Japan started growing slowly and the Bank of Japan stopped the unconventional monetary policy in early 2006. However, this was not the end of the grand experiment of the unconventional monetary policy. In September 2008 the "Lehman shock" hit the world economy and some central banks in the industrialized countries adopted an unconventional monetary policy to deal with the severe damages from the shock. Thus, the effectiveness of such policy is now not only a topic of curiosity but also an important topic for economic recovery in many countries.

The purpose of this paper is to examine the effectiveness of unconventional monetary policy in Japan. Firstly, the economic conditions and monetary policy in Japan for the lost two decades are reviewed in Section 2. In the following section, the discussions about the transmission mechanism of the unconventional monetary policy are examined. There are some possible routes for the monetary policy effect to be transmitted to real business activities, but it is pointed out that many past empirical studies are pessimistic about these routes and thus policy 
effectiveness. Instead of checking each route to examine the effectiveness, this paper takes another approach, a time-series analysis, which is carried out in Section 4. Finally Section 5 summarizes the discussions in this paper.

The analysis in this paper does not cover the recent policy to deal with the economic damages from the earthquake in March 2011, as not enough data has been accumulated. Thus, the analysis here is limited to the unconventional monetary policy that was implemented to fight against the problems after the burst of the economic bubble and against the Lehman shock.

\section{Unconventional Monetary Policy}

\subsection{Monetary Policy since the Late 1990's}

Unconventional monetary policy by the Bank of Japan (BOJ) started in the late 1990s. It was when Japan had been facing difficulties after the burst of the economic bubble in the early 1990s. Asset prices, such as stock prices and land prices, fell rapidly. As shown in Figure 1, the economy slowed down and even experienced a negative growth in some years.

Figure 1. Economic Growth and Inflation

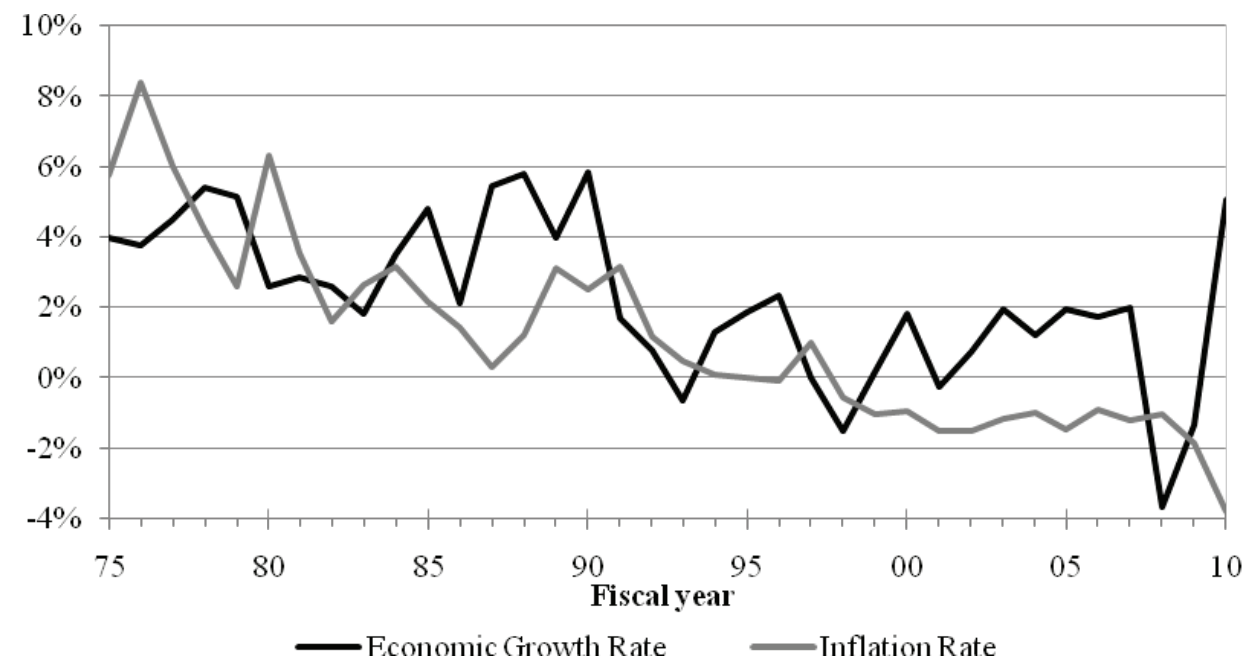

Source: Cabinet Office of Japan.

In the second half of the 1990s, it also had deflation. Many studies have attempted to identify the underlying cause of the economic slump. Miyao (2006, Chap. 8) examined the supply and demand factors by using econometric methods, and he reached the conclusion that the underlying cause lies on the supply-side factor. The expansion and burst of the economic bubble caused the sustained negative shock 
on productivity. This supply-side after-effect of the bubble damaged the demand-side of the economy, which led the economy to the long slump with moderate deflation.

In order to fight against the problem, the BOJ lowered the call rate, which is its policy rate, together with the BOJ's basic loan rate, as shown in Figure 2. Even with these aggressive rate cuts, the economy stayed in the slump, and the BOJ was gradually losing the room to lower the call rate further.

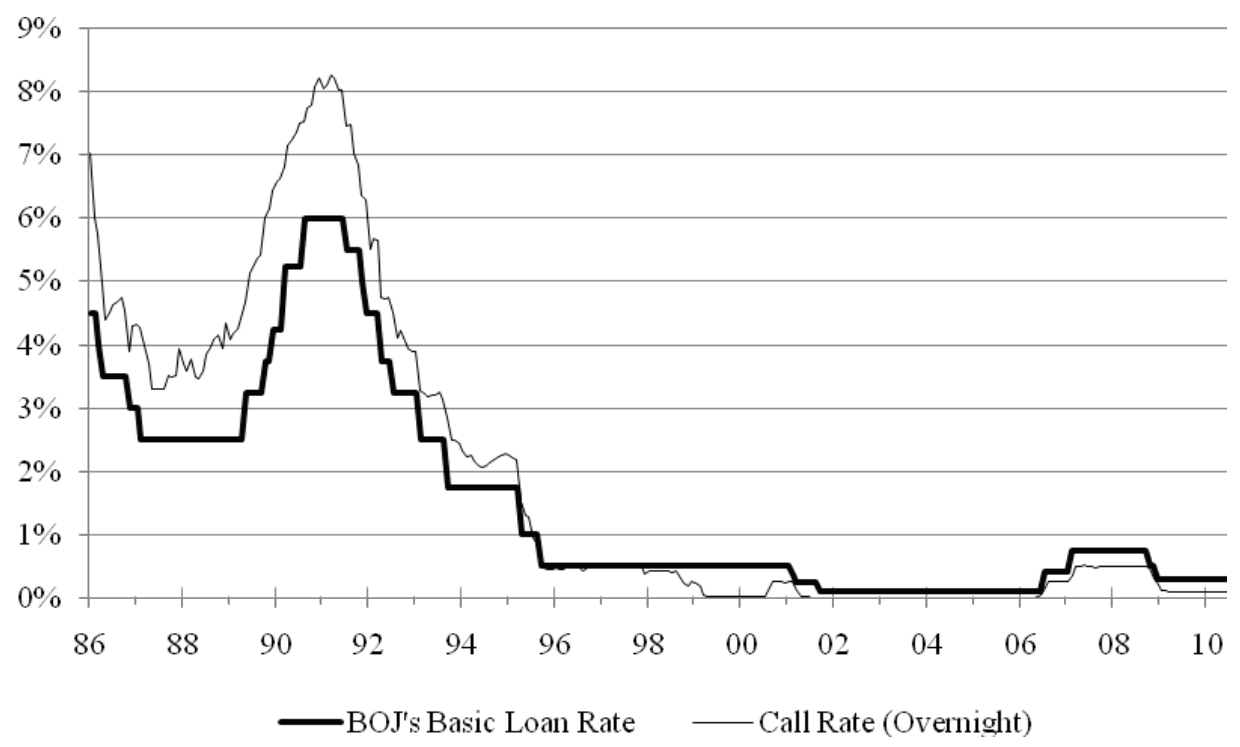

Figure 2. Basic Loan Rate and Call Rate

Source: BOJ. URL http://www.stat-search.boj.or.jp/index.html [accessed November 12, 2012]

Finally in February 1999, the BOJ lowered the call rate to virtually zero, which was maintained until August 2000. This is called the zero interest rate policy (ZIRP). The BOJ once raised the call rate, but started an even more aggressive and unprecedented policy called the quantitative easing (QE) in March 2001. In $\mathrm{QE}$, the operating target (policy variable) was no longer the call rate, but the current account balances that banks held at the BOJ. While the call rate was kept at zero, the BOJ kept supplying more and more funds to increase the current account balances. Figure 3 shows how the balances, which are the sum of the three components shown, were expanded for more easing.

Monetary policy is a policy to stabilize an economy by affecting its aggregate demand. If the underlying cause of the Japanese slump is on the supply-side as Miyao (2006) argued, then monetary policy cannot remove the cause. Even if monetary policy stimulates the economy, which is unlikely as discussed in this paper, it is only a temporary expedient, and the government needs to take measures to remove the supply-side cause. 
The Japanese economy started recovering slowly around 2002, and the BOJ ended QE in March 2006. Japan finally seemed to get out of the long tunnel of the slump, but the Lehman shock struck the world economy in September 2008. The central banks such as the FRB in the U. S., the ECB in Euro Zone, and the Bank of England in the U. K. were all forced to take some unconventional measures, and the BOJ was also forced back to unconventional monetary policy.

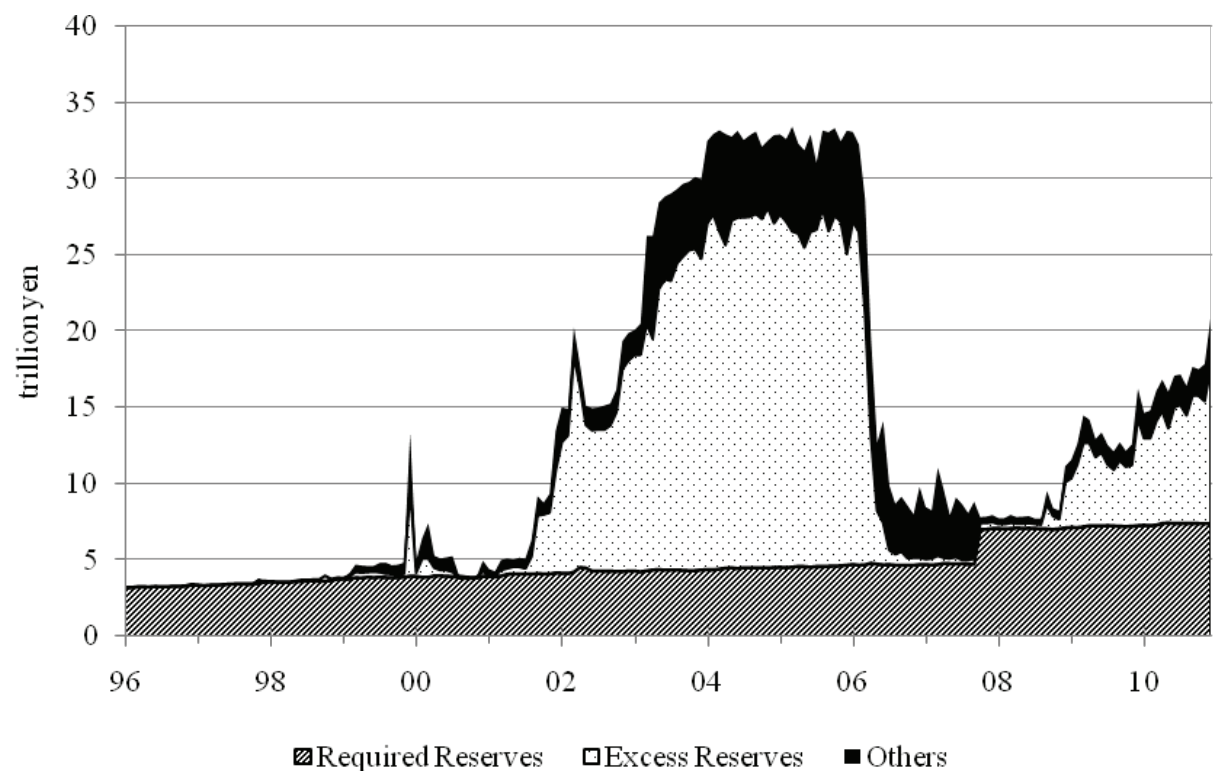

Figure 3. Current Account Balances

Source: BOJ. URL http://www.stat-search.boj.or.jp/index.html [accessed November 12, 2012]

\subsection{Features of Unconventional Monetary Policy in Japan}

Some features of unconventional monetary policy are examined here. Unconventional monetary policy was undertaken in Japan in the periods of ZIRP (February 1999 to August 2000), QE (March 2001 to March 2006), and the policy against the Lehman shock (PALS, from September 2008).

Its first feature is that unconventional monetary policy contains quantitative easing by supplying funds to the current accounts that banks hold at the BOJ. Figure 3 shows such quantitative expansion in QE and PALS. In the ZIRP, this feature is not apparent in the figure, but the current account balances at the BOJ increased by $40 \%$ from 3.6 trillion yen (average from January 1997 to January 1999) to 5.1 trillion yen during the ZIRP (average from February 1999 to July 2000 - with the exception of December 1999 when the year 2000 computer problem arose). 
For quantitative easing, the BOJ used various measures, including some unconventional ones. However, most of the funds were supplied via purchasing Japanese Government Bonds (JGBs). In fact, JGB holdings of the BOJ expanded from 47 trillion yen in January 1999 to 100 trillion yen in March 2004.

The huge supply of funds was considered to over exceed the demand by banks. Most of the funds were not used but piled up as excess reserves, as shown in Figure 3. Tanaka $(2006,2009)$ carried out an econometric analysis and concluded that the realized amount of funds exceeded the estimated demand by banks.

The second feature of unconventional monetary policy is commitment; the BOJ committed itself to keeping the unconventional monetary easing policy for a sufficient length of time. The BOJ announced to continue the ZIRP "until wiping out the concern about deflation," QE "until the consumer price index (excluding perishables, on nationwide statistics) registers stably a zero percent or an increase year on year," and PALS "until it (the BOJ) judges that price stability is in sight on the basis of the understanding of medium- to long-term price stability." Some argue that the commitment has an unconventional effect, and such effect will be discussed in Subsection 3.2.

Table 1. Funds Supplied by the Unconventional Measures

\begin{tabular}{|c|c|c|c|c|}
\hline BOJ's total assets & \multicolumn{2}{|c|}{ QE } & \multicolumn{2}{c|}{ PALS } \\
\hline Stock purchases from banks & 133.7 & $\begin{array}{c}\text { Mar.01-Feb. 06, } \\
\text { average }\end{array}$ & 119.6 & $\begin{array}{c}\text { Sep. 08-Jan. 11, } \\
\text { average }\end{array}$ \\
\hline ABS purchases & 2.0 & Sep. 04 & 1.5 & May, 10 \\
\hline $\begin{array}{c}\text { Special funds-supplying operations to fa- } \\
\text { cilitate corporate financing }\end{array}$ & 0.3 & Aug. 04 & & May, 09 \\
\hline Outright purchases of CPs & & & 7.5 & Mar. 09 \\
\hline $\begin{array}{c}\text { Outright purchases of corporate bonds } \\
\text { sunds-provisioning measures to support } \\
\text { strengthening the foundations for eco- } \\
\text { nomic growth }\end{array}$ & & & 0.3 & Sep. 09 \\
\hline Asset purchase program & & & 1.5 & Dec. 10 \\
\hline $\begin{array}{c}\text { Outright purchases of CPs, cor- } \\
\text { porate bonds, ETFs, REITs }\end{array}$ & & & 0.3 & Jan. 11 \\
\hline Fixed-rate operations & & & 25.6 & Jan. 11 \\
\hline
\end{tabular}

Source: BOJ. URL http://www.stat-search.boj.or.jp/index.html [accessed November 12, 2012].

The third feature is that the BOJ used some unconventional measures to supply funds, and some of them are purchases of risky assets. The BOJ, just like many other central banks, had limited its market operation to purchasing only safe 
assets, such as JGBs, CDs, and repurchase agreements (RAs) of CPs. However, in the unconventional monetary policy periods, the BOJ purchased risky assets, such as stock, ABS, ETFs, and REITs. It also made outright, not RA, purchases of corporate bonds and CPs rather that RAs.

Table 1 shows these unconventional measures together with the other unconventional measures by the BOJ. The amounts of risky assets purchased are small compared with the BOJ's total assets, but the importance of purchasing the risky assets resides not in the quantity but in the quality of assets.

\section{Transmission Mechanism of Monetary Policy}

\subsection{Conventional Transmission Mechanism}

This section explores the transmission mechanism of monetary policy, i.e. how the monetary policy effect is transmitted from a central bank to real business activities. The BOJ lowers the call rate and increases the amount of reserves, which means less costs and more available funds for banks to make loans. Then, the banks change their behaviour to make more loans, which stimulates the real business activities. There is another route at the bottom of the diagram; a cut in the call rate lowers the interest rates in the long-term financial markets such as the bond market via arbitrage between the call market and others.

The mechanism through these routes is valid only when the call rate can be altered. However, at zero, the call rate cannot be lowered. Even if banks receive funds as current account balances, they do not have any incentive to expand loans because the cost of making loans, which is the call rate, stays unchanged. The mechanism through the route at the bottom of the diagram is not valid either, as no arbitrage transactions are made without any change in the call rate. Hence, the conventional transmission mechanism does not work when the call rate is at zero.

\subsection{Unconventional Transmission Mechanism}

For monetary policy with the call rate at zero to be effective, two new ideas are proposed (shown as shaded routes in Figure 4). One of them is the commitment effect, where commitment is placed to the continuing monetary easing policy. This effect is considered to lower long-term interest rates such as bond rates and is enabled by two mechanisms. Firstly, current long-term interest rates are known to be the average of current and future short-term interest rates such as the call rate, and so the commitment to keeping the call rate at zero lowers current long-term interest rates. Secondly, the commitment to continue supplying funds affluently reduces liquidity risk. Thus, banks do not have to worry about the possibility of falling short of funds in the future, and so banks have no need to borrow funds in 
the long-term, which lowers the long-term interest rates. The commitment effect lowers the long-term interest rates, which should stimulate real business activities.

The commitment effect has been examined empirically by some past studies. Most of them, such as Shiratsuka et al. (2010), did not find any evidence to verify the effect in Japan. The other idea is the portfolio rebalance effect. If banks are forced to hold huge amount of funds at the non-interest bearing current accounts at the BOJ, then sooner or later banks will rebalance their portfolio by shifting a part of the funds to interest bearing risky assets, such as loans. Oda and Ueda (2005) examined this effect empirically, but they did not find any evidence to verify the effect.

\subsection{Macro Prudential Policy and Credit Easing}

Many studies, including this paper, are pessimistic about the effectiveness of unconventional monetary policy to stimulate economy. However, many admit that the policy contributed to stabilizing the financial system in Japan. For example, in the late 1990s, even major banks faced difficulties, and the ZIRP helped these banks by supplying funds affluently, which avoided possible financial crisis.

The policy to stabilize financial systems is called prudential policy, and it is used to focus on individual banks and other financial institutions. However, Japan's experience in the late 1990s was to supply funds to the financial sector as a whole, not to individual institutions. The prudential policy to focus on the financial sector as a whole is called macro prudential policy, and recently it has been attracting considerable attention.

As discussed above, the BOJ supplied most of funds via conventional measures such as JGB purchases. However, the FRB in the U. S. took an aggressive measure to purchase a substantial amount of risky assets after the Lehman shock in order to stabilize the American financial system. Recently, the BOJ has also adopted additional unconventional measures, though the amounts are small as seen in Table 1. Such purchases of risky assets by the central bank are called credit easing.

By purchasing risky assets, a central bank reduces the risk in the financial sector, and thus eases the credit conditions of the sector. However, credit easing has a serious side effect. By holding risky assets, the central bank risks its own credibility. Once its credibility is damaged, then it would jeopardize the nation's financial system. With this side effect, caution is needed in the use of credit easing.

The above discussion does not mean that quantitative easing without credit easing has no side effect. Quantitative easing itself is pointed out to have several problems, such as its adverse effect on the call market and a possible problem arising from ending quantitative easing. ${ }^{13}$ It also has a serious effect in weakening the governmental fiscal discipline if a central bank purchases a large amount of

13 With affluent funds piled up at the current accounts at the BOJ, banks did not need to borrow in the call market. Thus, the market shrank to such a degree that it did not function well. 
government bonds (like the BOJ), which possibly damages the credibility of central bank. (Ueda, 2004). In Japan, the BOJ gained its independence from the government by the new Bank of Japan Act in 1998, and so the government cannot force the BOJ to purchase more JGBs. However, from time recently some government officials express their opinions to suppress the independence.

\section{Effectiveness of Monetary Policy: A Time-Series Analysis}

The possible transmission mechanism of the unconventional monetary policy has been explored and discussed to such a degree that many studies have obtained pessimistic empirical results on the effectiveness of the policy. Besides examining each route of the mechanism, there is another way to check the effectiveness regardless of the route, which is a time-series analysis.

Many studies carried out such time-series analyses, and found no evidence to support the policy effectiveness during the unconventional monetary policy periods in Japan, such as Fujiwara (2006) and Tanaka (2006). One of the few exceptions is Honda et al. (2010). They concluded that the increases in the target level of current account balances at the BOJ affected the real business activities via increases in stock prices, though they failed to explain how the increases in the target level increased the stock prices.

In the residual of this paper, a time-series analysis is carried out to examine not only the ZIRP and QE but also the PALS. The data used by Tanaka (2006) is updated to include the data in PALS period, and the same regime-shifting econometric method is used. The estimation model used here is a VAR model of three variables: thus, call rate, reserves, and production. To examine any change in the policy effectiveness, it is necessary for the VAR model to shift from time to time, and so the regime-shifting method by Hamilton (1990) is used. For the details of the estimation method, please refer to Tanaka (2011).

The data used here is the monthly data shown in Table 2, and the sample period is from January 1979 to December 2010. Please note that the data from 2011 is not included in order to omit the influence of the earthquake disaster.

Table 2. The Data Used

\begin{tabular}{|c|c|c|}
\hline Variables & Data & Source \\
\hline Call rate & Collateralized overnight call rate & BOJ homepage \\
\hline Reserves & $\begin{array}{c}\text { otal reserves (monthly average, season- } \\
\text { ally adjusted) }\end{array}$ & BOJ homepage \\
\hline Production & $\begin{array}{c}\text { Industrial production index } \\
\text { (year 2005=100, seasonally adjusted) }\end{array}$ & $\begin{array}{c}\text { Homepage of Ministry of Economy, } \\
\text { Trade, and Industry }\end{array}$ \\
\hline
\end{tabular}

Source: the Author own search query. 
In the estimation, the model has three regimes, each of which is represented by one of the three different estimated VAR models. The estimation shows at what point Japan was in which regime or model. Since the policy effectiveness can be checked by examining each regime or model, it reveals when the policy was effective. The empirical results are as follows. The estimated probability of each regime is shown in Figure 5. The figure is an area chart with the probabilities of all three regimes stacked up.

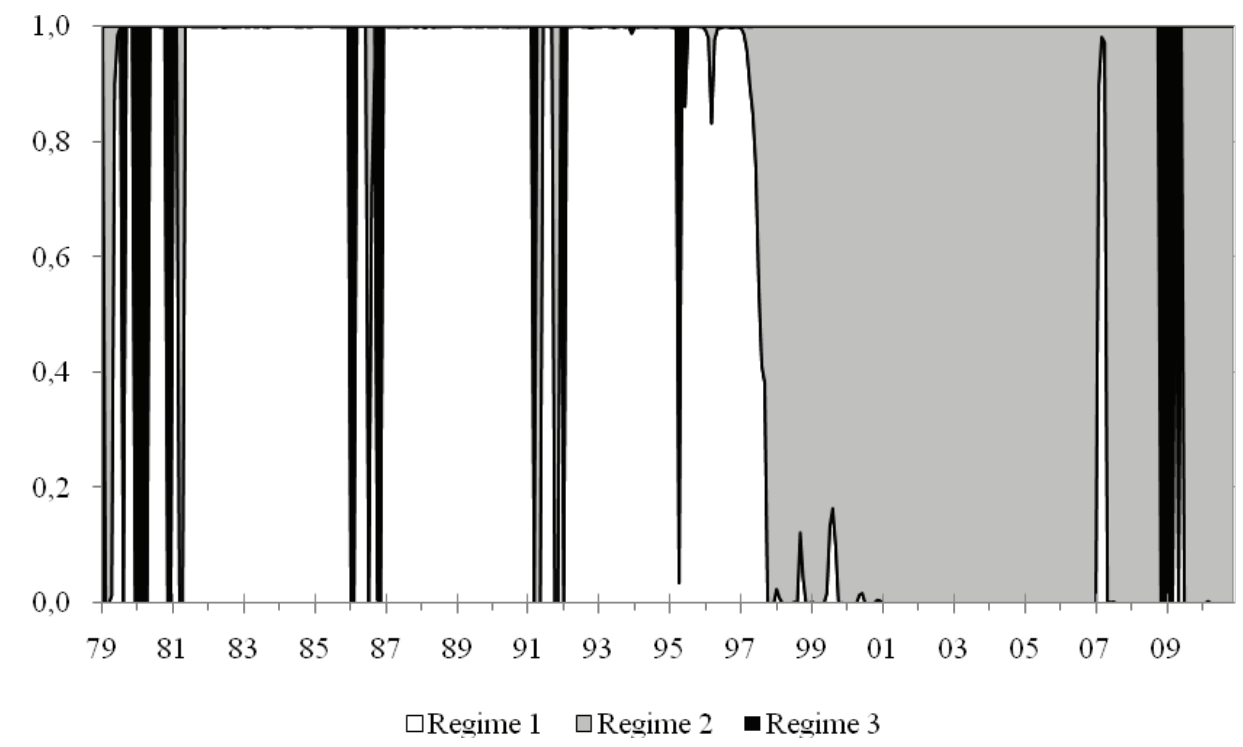

Figure 5. Probabilities of Regimes

Source: the Author own search query

Up to the end of 1997 , Regime 1 usually had a probability nearly equal to one, which means that Japan was most likely to be in Regime 1. Since this is the period when the BOJ undertook conventional monetary policy, Regime 1 is considered to be the regime of conventional monetary policy. From the beginning of 1998, Japan was usually in Regime 2, and Regime 2 is said to be the regime of unconventional monetary policy. Japan was in Regime 3 for only limited periods, such as in 1980 when the second oil shock hit the world, and in late 2008 to early 2009 when that Lehman shock hit the world. Regime 3 is said to be the regime of shocks. The policy effectiveness in each regime is examined by checking the causality among three variables in the estimated VAR models.

The thick arrows mean strong causality, and the narrow arrow means a weak one. The positive and negative signs are directions of change; a positive sign means that an increase in a cause variable leads to its result variable to increase, 
and vice versa. ${ }^{14}$ Regime 3 is not shown, because it had only few months to prevail, and any statistically significant results cannot be obtained.

Causality in Regime 1 suggests that the monetary policy is effective. The BOJ lowers the call rate, which increases the reserves and then expands the production. In Regime 2 , many causality arrows are lost, and the only narrow arrow goes from the call rate to reserves with the wrong sign. In Regime 2, the monetary policy is ineffective.

The findings from the above time-series analyses are as follows. The period before 1997 is when the BOJ was taking conventional monetary policy, which was effective. In 1998, a little earlier than the ZIRP started, the monetary policy lost its effectiveness. It stayed ineffective in most of time thereafter, and it was in this period that the BOJ was mostly undertaking the unconventional monetary policy.

\section{Conclusion}

This paper examined the unconventional monetary policy in Japan. Its features were examined, and then some possible routes of the transmission mechanism for the policy to aff ect real business activities were explored. The conventional routes are invalid since the call rate is at zero. The unconventional routes, the commitment effect and portfolio rebalance effect were examined; however, most of the past empirical studies show pessimistic results about these effects.

This paper then carried out time-series analyses among the call rate, reserves, and production. The estimation results show that the policy was effective in the period of conventional monetary policy, and that it was ineffective roughly in the period of the unconventional one.

The unconventional monetary policy in Japan is considered to have contributed to stabilizing the financial system, and recently such macro prudential policy is becoming important. Credit easing can be a part of macro prudential policy, but it risks the credibility of the central bank. Unconventional monetary policy, without credit easing, has the danger of losing fiscal discipline, which might jeopardize the credibility of the central bank. Caution is required when using an unconventional monetary policy.

${ }^{14}$ Causality here is the Granger causality, and in order to avoid the problems arising from unit roots and co-integration, the method proposed by Toda and Yamamoto (1995) is used. The VAR models' lag length determined by Akaike's information criterion is 4, and one more lag is added for Toda and Yamamoto's method. The directions of change are determined by estimating the impulse responses. 


\section{References}

Fujiwara, I. (2006). "Evaluating Monetary Policy When Nominal Interest Rates Are Almost Zero." Journal of Japanese International Economies 20: 434-53.

Hamilton, J. D. (1990). “Analysis of Time Series Subject to Changes in Regime." Journal of Econometrics 45(1-2): 39-70.

Honda, Y., Y. Kuroki, and M. Tachibana. (2010). "Quantitative Easing Policy: Empirical Analysis on the Japanese Experience, 2001-2006 [in Japanese].” Financial Review (Journal of Policy Research Institute, Ministry of Finance) 99: 59-81.

Miyao, R. 2006. Time-Series Analysis of Macro Monetary Policy: Theoretical and Empirical Studies on Policy Effect [in Japanese]. Tokyo:Nikkei.

Oda, N. and K. Ueda. (2005). "The Effects of the Bank of Japan's Zero Interest Rate Commitment and Quantitative Monetary Easing on the Yield Curve: A Macro-Finance Approach.” Japanese Economic Review 58(3): 303-328.

Shiratsuka, S, Y. Teranishi, and J. Nakajima. (2010). "The Effect of Monetary Policy Commitment: The Case of Japan [in Japanese]." Kin-yu Kenkyu (Journal of Institute for Monetary and Economic Studies, Bank of Japan). 29(3): 239-266.

Tanaka, A. (2006). Monetary Policy in Japan: Econometric Analysis of Regime Shifting [in Japanese]. Tokyo:Yuhikaku.

Tanaka, A. (2009). "Unconventional Monetary Policy and Reserve Market [in Japanese]." Journal of Economics of Kwansei Gakuin University. 63(3): 241-261.

Tanaka, A. 2011. "Unconventional Monetary Policy in Japan: Its Effectiveness and Problems [in Japanese]." in Possibility of Monetary Policy to Stimulate Japanese Economy (Report of Kansai Institute of Social and Economic Research): 39-58.

Toda, H. Y. and T. Yamamoto. (1995). "Statistical Inference in Vector Autoregressions with Possibly Integrated Processes." Journal of Econometrics. 66(1-2): 225-250.

Ueda, K. (2004). "Capital and Central Bank [in Japanese]." Review of Monetary and Financial Studies. 21: 1-12. 